\title{
Sex differences in weight perception and weight gain among Black college students in the USA
}

\section{Jounghee Lee ${ }^{1 \oplus}$, Jaesin $\mathrm{Sa}^{2}{ }^{\oplus}$, Jean-Philippe Chaput ${ }^{3 \oplus}{ }^{\oplus}$ James Heimdal $^{4}{ }^{\oplus}$, Beatrice Nelson ${ }^{5}$, Beom-Young $\mathrm{Cho}^{6 \oplus}$, Elizabeth Kwon ${ }^{7}$}

\author{
${ }^{1}$ Department of Food and Nutrition, Kunsan National University, Gunsan, Korea \\ ${ }^{2}$ College of Education and Health Sciences, Touro University, Vallejo, CA, USA \\ ${ }^{3}$ Department of Pediatrics, University of Ottawa, Ottawa, ON, Canada \\ ${ }^{4}$ Department of Human Performance and Sport Sciences, Tennessee State University, Nashville, TN, USA \\ ${ }^{5}$ Department of Kinesiology, University of Maryland Eastern Shore, Princess Anne, MD, USA \\ ${ }^{6}$ Division of Public Health Sciences, Washington University, St. Louis, MO, USA \\ ${ }^{7}$ Department of Human Development and Family Science, University of Georgia, Athens, GA, USA
}

Received: September 15, 2020

Revised: January 5, 2021

Accepted: January 27, 2021

Corresponding author:

Jaesin Sa

College of Education and

Health Sciences, Touro

University, 310 Moore St.

Vallejo, CA 94592, USA

E-mail: jaesin.sa@tu.edu

\section{ABSTRACT}

Objectives: The aims of this study were to examine the prevalence of overweight/obesity and to explore sex differences in body weight perceptions and correlates of weight gain among Black students at 2 historically Black colleges and universities (HBCUs) in the USA.

Methods: Participants completed a paper-based survey, and their height and weight were measured (67\% completion rate).

Results: The overweight and obesity rates were $33.8 \%$ and $26.9 \%$, respectively. More females than males accurately assessed their weight $(p<0.05)$. Body weight underestimation was associated with male sex, excellent/very good perceived overall health, and not being informed by a doctor of having overweight or obesity $(p<0.01)$. Higher odds of $\geq 5 \%$ weight gain were related to female sex, living on campus, and not being informed by a doctor of having overweight or obesity $(p<0.05)$.

Conclusion: Given the high overweight and obesity rates among Black students, HBCUs in the USA should develop intervention strategies for the prevention and management of overweight and obesity. College health educators at HBCUs need to provide regular check-ups or health screenings that help male students perceive their weight accurately and prevent weight underestimation. It is important for HBCUs to monitor and address weight gain among Black students as early as possible.

Keywords: Obesity; Sex characteristics; Students; Universities; Weight gain; Weight perception

\section{Introduction}

The prevalence of overweight/obesity among college students in the USA increased from 
31.3\% in 2008 to 39.7\% in 2019 [1,2]. Overweight/obesity and weight gain during adulthood are related to an increased risk of diabetes, cardiovascular disease, and some forms of cancer [3]. Given that the prevalence of overweight/obesity in adults aged 20 to 39 years is about twice as high as that in adolescents aged 12 to 19 years [4], the transition from adolescence to adulthood is a critical period for weight gain $[5,6]$, and college years may be a time of particular risk for overweight and obesity [7]. Maintaining an active lifestyle and healthy eating habits could be challenging for college students due to a lack of family support and established routines [7]. Thus, when students transition from high school to college, many face drastic changes in their environment and residence that may influence health behaviors such as diet and exercise [5]. The health behaviors of college students are important because health habits established during their college years could affect life-long weight struggles and future health problems [5]. Despite reports of rapid weight gain during the college years [7], investigations of weight gain among college students have been scarce [8].

Unlike investigations of overweight and obesity among US adults that have provided race/ethnicity-specific rates of overweight and obesity, very few studies have examined racial/ethnic differences in overweight and obesity among US college students [9]. In 2007, a US national study of 24,613 students from 119 four-year colleges reported that non-Hispanic Blacks had higher rates (38.3\%) of overweight and obesity than non-Hispanic Whites (26.7\%), non-Hispanic Asians (16.4\%), and Hispanics (30.2\%) [9]. The high rates of overweight/obesity in Black college students may be due, in part, to body weight perceptions [10] and associated weight management behaviors [11]. Evidence shows that accurate weight perception plays an important role in weight loss attempts [11]. Furthermore, weight underestimation is a predictor of weight gain over time [10] and a barrier to weight management behaviors among adults [12].

Sex [13] and race/ethnicity [14] are crucial determinants of body weight perception. In a statewide school-based survey, $24.5 \%$ of male adolescents underestimated their weight, which was 3 times higher than the prevalence reported in female adolescents [13]. A similar sex difference was reported in Black college students [15]. In addition, weight underestimation was more prevalent in Black female adolescents than in their White counterparts [13]. To date, however, a paucity of research exists on weight perception in Black college students [16] despite their higher rates of overweight and obesity than other racial/ethnic groups [9]. Thus, the current study aimed to investigate the prevalence of overweight/obesity and to examine sex differences in body weight perceptions and correlates of weight gain among Black college students at 2 historically Black colleges and universities (HBCUs).

\section{Materials and Methods}

\section{Participants}

A purposive sample of Black students from 2 HBCUs in the USA was recruited for this cross-sectional study. After the Institutional Review Boards at Tennessee State University (IRB No: HS2015-3675) and University of Maryland Eastern Shore (IRB No: \#2016-016) approved the protocol, 325 undergraduate students enrolled in health courses were invited to participate in a paper-based survey in March 2016. A total of 318 students completed the survey. All participants provided written consent for their personal data to be used. Twenty-five participants at each university were randomly selected and each of them received a $\$ 25$ gift card as reimbursement. This sample initially consisted of 278 Black students, 4 Native Hawaiian or Pacific Islander students, 25 White students, and 11 students of other racial backgrounds. Data from 278 Black students, our population of interest, were used for the current study. We excluded 59 participants who did not report anthropometric characteristics $(n=1)$ or socio-demographic data $(n=10)$. The present study focused on investigating the healthrelated variables that are correlated with weight gain. Thus, participants $(n=48)$ with missing responses pertinent to the health-related items were excluded. The final sample was composed of 219 participants, reflecting a completion rate of $67 \%$.

\section{Measures}

We developed a 34-item paper questionnaire adapted from the following previously validated and reliable instruments: the American College Health Association-National College Health Assessment [17], National Longitudinal Survey of Youth [18], and National Health and Nutrition Examination Survey [19]. The questionnaire was pilot-tested with 10 Black students at the $2 \mathrm{HBCUs}$ to evaluate the questionnaire wording and respondents' understanding of questions. Data from the pilot test were not included in the study.

To measure body mass index (BMI), anthropomorphic data were collected using a Detecto scale (Detecto Scale Company, Webb City, MO, USA). After completing the questionnaire, participants stood on the scale, wearing light clothes/no shoes, and their height and weight were measured twice. The mean of each measurement was recorded. BMI was calculated as weight (kilograms) divided by height (meters squared) [20]. Participants' BMI status 
was classified as follows: (1) underweight, $<18.5 \mathrm{~kg} / \mathrm{m}^{2}$; (2) normal weight, $18.5-24.9 \mathrm{~kg} / \mathrm{m}^{2}$; (3) overweight, $25.0-29.9 \mathrm{~kg} / \mathrm{m}^{2}$; and (4) obesity, $\geq 30 \mathrm{~kg} / \mathrm{m}^{2}$.

Body weight perception was measured by the question, "Do you consider yourself now to be...?" Response options were "underweight," "about the right weight," and "overweight." Body weight perceptions were divided into 3 categories based on the concordance, or lack thereof, between perceived weight status and actual BMI status, which was objectively measured and computed by the lead author: (1) underestimation (perceived weight status <BMI status); (2) accurate estimation (perceived weight status = BMI status); and (3) overestimation (perceived weight status > BMI status) [21]. Each student's weight change was computed by subtracting his/her self-reported weight in the previous year from his/her self-reported current weight. Weight gain was defined as a $\geq 5 \%$ increase in weight relative to weight 1 year ago [22,23]. Participants were categorized as having $\geq 5 \%$ or $<5 \%$ weight gain.

Questions on sociodemographic characteristics included the type of residence (on-campus vs. off-campus) and annual household income. The poverty threshold level was computed using the 2015 federal poverty level guidelines to determine poverty status [24]. Health behavior questions were asked to assess participants' dietary intake of alcohol, fruits, vegetables, soda, and fast foods. Questions about sedentary behavior were asked to measure time sitting on a typical day and daily television/video/computer screen time use. Health status questions were asked to gauge students' perceived health status and whether or not a doctor had ever informed them of their overweight status. Physical activity questions were asked to measure the number of days/week and minutes/day participants engaged in the following physical activities for 10 minutes: (1) walking or bicycling; (2) moderate-intensity sports, fitness, or recreational activities causing small increases in the breathing or heart rate; and (3) vigorous-intensity sports, fitness, or recreational activities causing large increases in the breathing or heart rate. These physical activity questions were used to create a metabolic equivalent (MET) variable that was calculated by multiplying walking/ bicycling by 4.0 , moderate-intensity activities by 4.0 , and vigorous-intensity activities by 8.0 [25]. Based on these MET values, participants' activity level was classified into 2 categories, inactive ( $<500 \mathrm{MET}-\mathrm{min} / \mathrm{wk})$ and active $(\geq 500$ MET-min/wk) [23,25].

\section{Data Analysis}

The chi-square test and the Cramer's V-test were performed to investigate the significance of differences in categorical variables (e.g., sociodemographic characteristics and health behaviors) and weight perceptions between male and female participants. Multivariable logistic regression models were developed to identify correlates of weight underestimation and $\geq 5 \%$ weight gain over 1 year among students with overweight or obesity. Independent variables in the multivariable logistic regression models were selected based on previous research that found associations with weight underestimation and weight gain [11,12,26,27]. All analyses were conducted with Stata ver. 13 (StataCorp., College Station, TX, USA). We set the level of significance at 0.05 .

\section{Results}

This study included a total of 219 participants with a mean age of 19.8 years (standard deviation, 1.5 years), of whom $54.8 \%$ were male. As shown in Table 1, 37.9\% of participants had an annual income $\geq \$ 60,000,27.4 \%$ had an annual income between $\$ 30,000$ and $\$ 59,999$, and $14.6 \%$ had an annual income $<\$ 30,000$. Almost 3 out of 4 participants lived on campus (74.0\%). The campus setting was a rural town for $64.8 \%$ of participants, while $35.2 \%$ of them were in a very large city.

The proportions of weight status were as follows: underweight, 2.3\%; normal weight, 37.0\%; overweight, 33.8\%; and obesity, $26.9 \%$. Sex was moderately associated with perceived overall health (Cramer's V $=0.283$ ). More females than males $(27.3 \%$ vs. $10.8 \% ; p=0.001$ ) perceived their overall health as fair or poor. More males than females ( $93.5 \%$ vs. $83.0 \% ; p=0.025$ ) reported $\geq 500$ MET-minutes/week of physical activity. Only $22.4 \%$ of participants consumed $\geq 3$ daily servings of fruits and vegetables. Almost half of participants (49.3\% and $46.6 \%$, respectively) consumed fast food $\geq 3$ times and drank a soft drink $\geq 3$ times in the past 7 days (Table 1 ).

As shown in Table 2, sex was moderately associated with body weight perceptions in all weight status categories: (1) normal weight group, Cramer's V=0.399; (2) overweight group, Cramer's V =0.290; and (3) obese group, Cramer's $\mathrm{V}=0.352$. Among participants with normal weight, more females than males ( $88.1 \%$ vs. $66.7 \% ; p=0.001$ ) estimated their body weight accurately. We observed similar results in participants with overweight or obesity, indicating that females had more accurate weight perceptions than males, regardless of their weight categories (Table 2).

Higher odds of body weight underestimation were associated with (1) male sex, (2) not being informed of being overweight by a doctor, and (3) being physically active ( $\geq 500$ MET-min/wk; $p<0.05$ ) (Table 3).

Higher odds of $\geq 5 \%$ weight gain were associated with (1) 
Table 1. Characteristics of participants

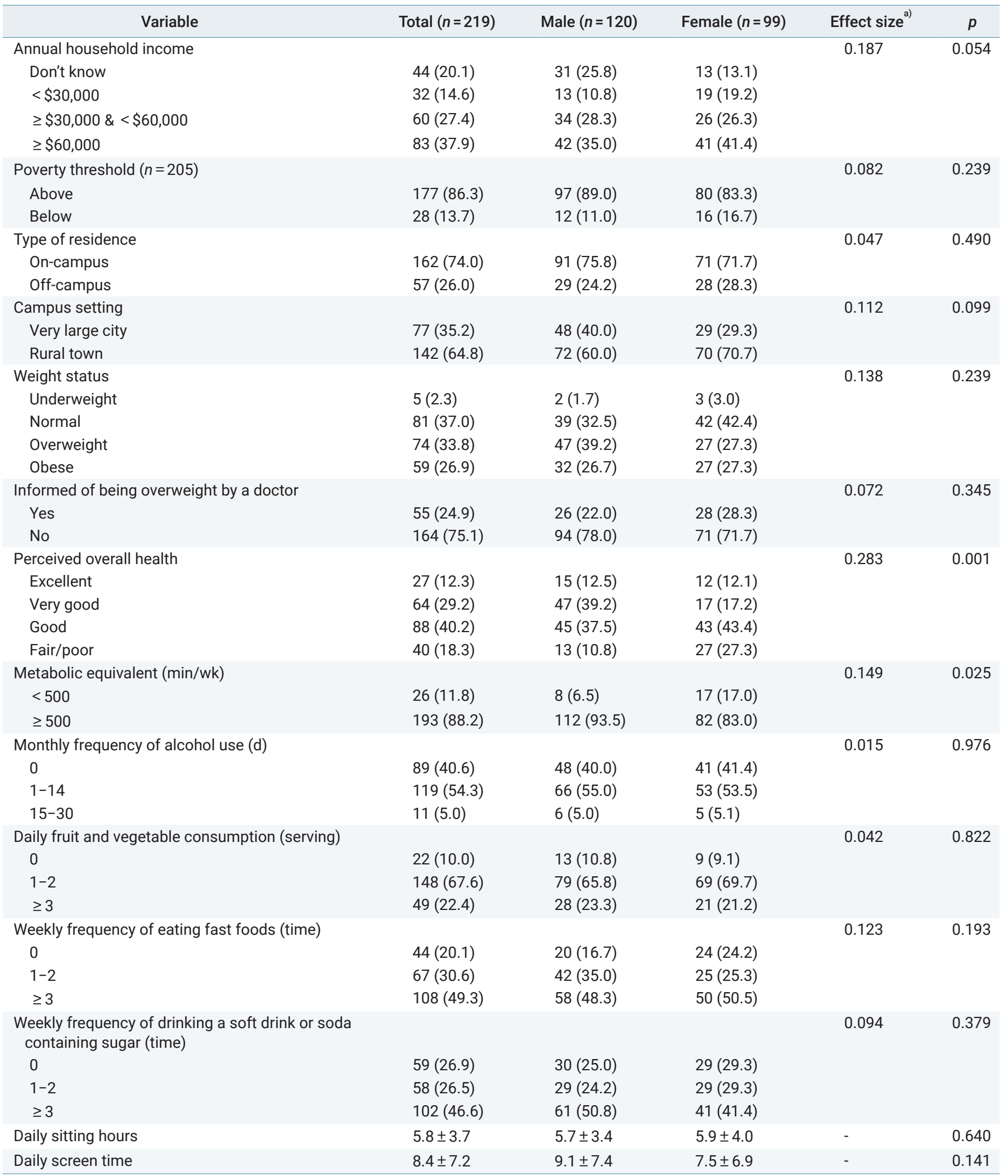

Data are presented as $n(\%)$ or mean \pm SD. The percentages may not add to 100 because of a lack of responses or rounding errors.

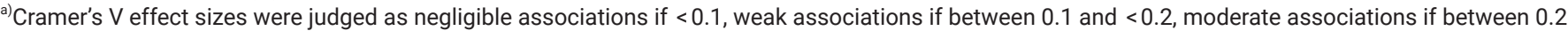
and $<0.4$, and strong if $\geq 0.4$. 
Table 2. Body weight perceptions by sex

\begin{tabular}{|c|c|c|c|c|c|}
\hline Variable & Total & Male & Female & Effect size ${ }^{\text {a) }}$ & $p$ \\
\hline Normal weight $(n=81)$ & & & & 0.399 & 0.001 \\
\hline Underestimation & $15(18.5)$ & $13(33.3)$ & $2(4.8)$ & & \\
\hline Overestimation & $3(3.7)$ & $0(0.0)$ & $3(7.1)$ & & \\
\hline Overweight $(n=74)$ & & & & 0.290 & 0.013 \\
\hline Underestimation & $56(75.7)$ & $40(85.1)$ & $16(59.3)$ & & \\
\hline Obese $(n=59)$ & & & & 0.352 & 0.007 \\
\hline Underestimation & $11(18.6)$ & $10(31.3)$ & $1(3.7)$ & & \\
\hline Accurate estimation & $48(81.4)$ & $22(68.8)$ & $26(96.3)$ & & \\
\hline
\end{tabular}

Data are presented as $n(\%)$. Underweight participants were not included in this table due to the small sample size $(n=5)$.

${ }^{a}$ Cramer's $V$ effect sizes were judged as negligible associations if $<0.1$, weak associations if between 0.1 and $<0.2$, moderate associations if between 0.2 and $<0.4$, and strong if $\geq 0.4$.

living on campus, (2) household income $(\$ 30,000-\$ 59,999)$, (3) being below the poverty threshold, (4) having fair or poor perceived health, (5) not being informed of being overweight by a doctor, (6) longer daily screen time, (7) eating fast food $\geq 3$ times/week, and (8) drinking a soft drink $\geq 3$ times/week $(p<0.05)$. Lower odds of weight gain were associated with male sex and eating $\geq 3$ servings of fruits and vegetables $(p<0.05)$ (Table 4 ).

\section{Discussion}

The present study aimed to fill a research gap by examining the prevalence of overweight/obesity and investigating sex differences in body weight perception and correlates of $\geq 5 \%$ weight gain in the past year in a sample of students at HBCUs. The overweight/obesity rate of students at HBCUs was found to be $60.7 \%$, which was much higher than that (38.3\%) of a nationally representative sample of Black college students in the USA [9]. In addition, the overweight/ obesity rate $(60.7 \%)$ in the current study was markedly higher than that $(36.8 \%)$ of a nationally representative sample of US college students who completed the American College Health Association-National College Health Assessment in 2016 [28].

Similar to other studies of college students finding that females estimated their body weight more correctly than males [11,15], the females in this study were significantly more likely than the males to accurately estimate their body weight, regardless of their weight categories. A previous study reported that among US adults with overweight or obesity, males were less likely than females to perceive their weight accurately [29]. A possible explanation is that males perceive a more muscular and athletic body type as an ideal shape because social norms among males may shape preferences for a heavier body [30,31]. Moreover, females may be scrutinized more intensely than males regarding social standards of beauty and in response may be more diligent at keeping records of their weight [32,33]. The present study showed that the prevalence of overweight/ obesity among male students in 2016 was 65.9\%, which was much higher than that of overweight/obesity (42.2\%) among male students who completed the American College Health Association-National College Health Assessment in the same year [28]. The higher overweight/obesity prevalence among male students in the current sample may be due, in part, to inaccurate body weight perceptions [34]. Research has shown that accurate weight perception is associated with the desire to lose weight [35] and plays an important role in maintaining a healthy weight $[14,36]$. There is a need to establish effective programs to prevent or rectify body weight misperceptions, especially in Black male college students at HBCUs. Thus, it is important for college health professionals at HBCUs to develop health education programs that help their male students perceive their weight accurately, which may result in a lower overweight/ obesity rate.

Excellent or very good perceived overall health was predictive of weight underestimation. Another possible cause of weight underestimation is visual weight status misperceptions, but this factor was not directly measured in the current study. Oldham and Robinson [37] found that frequent visual exposure to people with obesity can alter one's perception of how a healthy body weight appears and lead to an underestimation of weight. Therefore, given the high rates of overweight and obesity in Black communities [38,39], it is possible that heavy weights may appear normal and healthy in these settings and that those who underestimate their weight may also have a false sense of perceived good health [40]. In addition to 
Table 3. Correlates of body weight underestimation $(n=82)$ compared to correct body weight estimation $(n=129)$

\begin{tabular}{|c|c|}
\hline Variable & OR $(95 \% \mathrm{Cl})$ \\
\hline \multicolumn{2}{|l|}{ Age (y) } \\
\hline 18-19 & $1.02(0.59-1.78)$ \\
\hline$\geq 20$ & 1.00 \\
\hline \multicolumn{2}{|l|}{ Sex } \\
\hline Male & $4.46(2.40-8.30)^{\star \star \star}$ \\
\hline Female & 1.00 \\
\hline \multicolumn{2}{|l|}{ Campus setting } \\
\hline Very large city & $0.94(0.52-1.67)$ \\
\hline Rural town & 1.00 \\
\hline \multicolumn{2}{|l|}{ Type of residence } \\
\hline On-campus & $1.43(0.75-2.73)$ \\
\hline Off-campus & 1.00 \\
\hline \multicolumn{2}{|l|}{ Poverty threshold } \\
\hline Above & 1.00 \\
\hline Below & $1.04(0.46-2.35)$ \\
\hline \multicolumn{2}{|l|}{ Perceived overall health } \\
\hline Excellent/very good & 1.00 \\
\hline Good & $0.72(0.39-1.31)$ \\
\hline Fair/poor & $0.15(0.06-0.43)^{\star \star *}$ \\
\hline \multicolumn{2}{|c|}{ Informed of being overweight by a doctor } \\
\hline Yes & 1.00 \\
\hline No & $2.81(1.37-5.74)^{\star *}$ \\
\hline \multicolumn{2}{|c|}{ Metabolic equivalent (min/wk) } \\
\hline$<500$ & 1.00 \\
\hline$\geq 500$ & $3.21(1.05-9.85)^{*}$ \\
\hline Daily sitting hours & $1.04(0.96-1.12)$ \\
\hline Daily screen time & $1.05(0.99-1.11)$ \\
\hline \multicolumn{2}{|c|}{ Monthly frequency of alcohol use (d) } \\
\hline 0 & 1.00 \\
\hline $1-14$ & $0.91(0.51-1.62)$ \\
\hline $15-30$ & $1.86(0.52-6.57)$ \\
\hline \multicolumn{2}{|c|}{ Daily fruit and vegetable consumption (serving) } \\
\hline 0 & 1.00 \\
\hline $1-2$ & $0.88(0.35-2.27)$ \\
\hline$\geq 3$ & $0.45(0.15-1.35)$ \\
\hline \multicolumn{2}{|c|}{ Weekly frequency of eating fast foods (time) } \\
\hline 0 & 1.00 \\
\hline $1-2$ & $2.01(0.88-4.61)$ \\
\hline$\geq 3$ & $1.75(0.81-3.79)$ \\
\hline \multicolumn{2}{|c|}{$\begin{array}{l}\text { Weekly frequency of drinking a soft drink or } \\
\text { soda containing sugar (time) }\end{array}$} \\
\hline 0 & 1.00 \\
\hline $1-2$ & $1.33(0.61-2.90)$ \\
\hline$\geq 3$ & $1.77(0.89-3.51)$ \\
\hline
\end{tabular}

We excluded underweight participants $(n=5)$ and normal weight participants who overestimated their body weight $(n=3)$ due to the small cell size. $\mathrm{OR}$, odds ratio; $\mathrm{Cl}$, confidence interval.

${ }^{*} p<0.05,{ }^{* k} p<0.01,{ }^{* k *} p<0.001$. the aforementioned correlate of weight underestimation, not being informed by a doctor of having overweight or obesity was associated with weight underestimation. This underscores the important role that health care providers at student health centers can play when it comes to openly speaking about weight-related issues with Black students who underestimate their weight. Weight underestimation was reported to be more prevalent in Black college students than in other racial/ ethnic groups in a nationally representative sample of college students, thereby highlighting racial/ethnic differences in weight underestimation among US college students [14]. Therefore, it is important for college health educators at HBCUs to understand more correlates of weight underestimation and to provide regular check-ups or health screenings for their students. In addition, future research should include a large sample of Black students at HBCUs using probability sampling techniques.

This study found that $62.9 \%$ of participants who had overweight or obesity experienced weight gain, defined as a $5 \%$ or greater weight increase relative to weight 1 year ago, which is in accord with previous evidence that weight gain is one of the most common negative health consequences among college students [7]. Living on campus and not having been informed by a doctor of having overweight or obesity were associated with weight gain. The present study findings reinforce the importance of college health care providers, who can provide effective communication about weight gain for college students and, in particular, those at HBCUs. Overweight and obesity in college can be a powerful determinant of excess body weight in middle adulthood [41]. Colleges and universities are an ideal place to educate students on health behaviors and to promote healthy weight maintenance [9]. Considering that most colleges and universities have resources (e.g., student wellness programs and fitness centers) on campus, it is necessary for college health staff and campus administrators at HBCUs to promote healthy weight-related behaviors by encouraging students living on campus to use those resources. Moreover, it is imperative that HBCUs monitor and address weight gain among students as early as possible.

Limitations of this study include the cross-sectional nature of the data, which prevents a determination of causality between sociodemographic or behavioral factors and perceived weight or weight gain. Second, survey data were based on self-reports, which are susceptible to recall bias. However, unlike previous college obesity studies $[11,14,42]$ that were based on self-reported height and weight, this study used measured height and weight. A previous study reported that BMI values computed from 
Table 4. Correlates of weight gain ${ }^{a)}$ among overweight and obese students $(n=132)$

\begin{tabular}{|c|c|c|}
\hline Variable & $\geq 5 \%$ weight gain $(\%)$ & OR $(95 \% \mathrm{Cl})$ \\
\hline Total & 58.3 & \\
\hline \multicolumn{3}{|l|}{ Age $(y)$} \\
\hline 18-19 & 62.9 & $1.48(0.73-3.00)$ \\
\hline$\geq 20$ & 53.2 & 1.00 \\
\hline \multicolumn{3}{|l|}{ Sex } \\
\hline Male & 50.0 & $0.43(0.20-0.94)^{*}$ \\
\hline \multicolumn{3}{|l|}{ Campus setting } \\
\hline Very large city & 58.7 & $1.35(0.64-2.87)$ \\
\hline Rural town & 58.1 & 1.00 \\
\hline \multicolumn{3}{|l|}{ Type of residence } \\
\hline On-campus & 62.5 & $2.46(1.12-5.38)^{*}$ \\
\hline Off-campus & 47.2 & 1.00 \\
\hline \multicolumn{3}{|l|}{ Perceived overall health } \\
\hline Excellent/very good & 41.9 & 1.00 \\
\hline Good & 58.3 & $1.81(0.82-4.01)$ \\
\hline Fair/poor & 82.8 & $5.03(1.62-15.63)^{\star *}$ \\
\hline \multicolumn{3}{|c|}{ Informed of being overweight by a doctor } \\
\hline Yes & 51.0 & 1.00 \\
\hline No & 63.7 & $2.07(1.01-4.30)^{*}$ \\
\hline \multicolumn{3}{|c|}{ Metabolic equivalent (min/wk) } \\
\hline$<500$ & 81.8 & 1.00 \\
\hline$\geq 500$ & 55.9 & $0.35(0.07-1.69)$ \\
\hline \multicolumn{3}{|c|}{ Monthly frequency of alcohol use (d) } \\
\hline 0 & 85.7 & 1.00 \\
\hline $1-2$ & 57.3 & $0.16(0.02-1.35)$ \\
\hline$\geq 3$ & 48.3 & $0.09(0.01-0.83)^{*}$ \\
\hline \multicolumn{3}{|c|}{ Weekly frequency of eating fast foods (time) } \\
\hline 0 & 44.0 & 1.00 \\
\hline $1-2$ & 59.5 & $2.55(0.98,7.04)$ \\
\hline$\geq 3$ & 63.1 & $2.67(1.04,6.86)^{*}$ \\
\hline \multicolumn{3}{|c|}{ Weekly frequency of drinking a soft drink or soda containing sugar (time) } \\
\hline 0 & 46.9 & 1.00 \\
\hline $1-2$ & 58.3 & $1.88(0.65-5.38)$ \\
\hline$\geq 3$ & 64.1 & $3.21(1.21-8.55)^{\star}$ \\
\hline \multicolumn{3}{|l|}{ Body weight perception } \\
\hline Underestimation & 62.7 & $0.98(0.49-1.99)$ \\
\hline Accurate estimation & 63.1 & 1.00 \\
\hline
\end{tabular}

OR, odds ratio; $\mathrm{Cl}$, confidence interval.

a) Defined as a $5 \%$ or greater weight increase relative to weight 1 year ago.

${ }^{*} p<0.05,{ }^{* *} p<0.01$. 
self-reported height and weight were $1.16 \mathrm{~kg} / \mathrm{m}^{2}$ lower than measured BMI values. In the current study, participants' BMI was accurately measured, and self-reporting bias of BMI was not present. Third, caution is needed to generalize our findings to students at other HBCUs as the study data were collected at only 2 HBCUs with a small sample size. Fourth, multivariable logistic regression in this study could not take covariates into account because it produced unstable adjusted ratios and 95\% confidence intervals due to the small sample size. Finally, residual confounding by unmeasured variables is always a possibility when dealing with observational studies, and a broader list of correlates of weight perception and weight gain may be needed.

Despite these limitations, the present study adds to the knowledge base by reporting the prevalence of overweight/ obesity and investigating sex differences in body weight perceptions and correlates of weight gain (defined as a $5 \%$ or greater weight increase in comparison with weight 1 year ago) in students at 2 HBCUs. The college years are associated with many life changes that can impact behaviors in a way that is conducive to weight gain [5]. Examples include unhealthy eating behaviors, reduced physical activity, increased sedentary behavior including screen time, and high levels of stress [27,43,44]. More importantly, the factors that can lead to weight gain can be quite different between individuals [5]. A one-size-fitsall approach aimed at addressing the barriers to healthy behaviors and contributors to weight gain is unlikely to work in such a context. Instead, it is important to develop individualized health promotion programs for college students and to address the root causes of the problem to maximize success.

\section{Notes}

\section{Ethics Approval}

The study was approved by the Institutional Review Board of Tennessee State University (IRB No: HS2015-3675) and University of Maryland Eastern Shore (IRB No: \#2016-016). All participants provided written consent for their personal data to be used.

\section{Conflicts of Interest}

The authors have no conflicts of interest to declare.

\section{Funding}

None.

\section{Availability of Data}

All data generated or analysed during this study are included in this published article.

\section{References}

1. American College Health Association (ACHA). American College
Health Association-National College Health Assessment II: reference group executive summary, Fall 2008 [Internet]. Baltimore, MD: ACHA; 2009 [cited 2016 Aug 16]. Available from: https://www.acha.org/ NCHA/ACHA-NCHA_Data/Publications_and_Reports/NCHA/Data/ Reports_ACHA-NCHAII.aspx.

2. American College Health Association (ACHA). American College Health Association-National College Health Assessment III: reference group executive summary, Fall 2019 [Internet]. Silver Spring, MD: ACHA; 2020 [cited 2020 May 16]. Available from: https://www.acha.org/NCHA/ACHANCHA_Data/Publications_and_Reports/NCHA/Data/Reports_ACHANCHAIII.aspx.

3. National Center for Health Statistics. Health, United States, 2007, with chartbook on trends in the health of Americans [Internet]. Hyattsville, MD: National Center for Health Statistics; 2007 [cited 2016 Jun 29]. Available from: http://www.cdc.gov/nchs/data/hus/ hus07.pdf\#listfigures.

4. Ogden CL, Carroll MD, Kit BK, et al. Prevalence of childhood and adult obesity in the United States, 2011-2012. JAMA 2014;311:80614.

5. Cluskey M, Grobe D. College weight gain and behavior transitions: male and female differences. J Am Diet Assoc 2009;109:325-9.

6. Crombie AP, Ilich JZ, Dutton GR, et al. The freshman weight gain phenomenon revisited. Nutr Rev 2009;67:83-94.

7. Calamidas EG, Crowell TL. A content analysis of college students health behaviors. Am J Health Educ 2018;49:133-46.

8. Yan Z, Harrington A. Factors that predict weight gain among first-year college students. Health Educ J 2020;79:94-103.

9. Nelson TF, Gortmaker SL, Subramanian SV, et al. Disparities in overweight and obesity among US college students. Am J Health Behav 2007;31:363-73.

10. Lynch E, Liu K, Wei GS, et al. The relation between body size perception and change in body mass index over 13 years: the Coronary Artery Risk Development in Young Adults (CARDIA) study. Am J Epidemiol 2009;169:857-66.

11. Gibbs HD, Pacheco C, Yeh HW, et al. Accuracy of weight perception among American Indian tribal college students. Am J Prev Med 2016;51:e139-44.

12. Lynch EB, Kane J. Body size perception among African American women. J Nutr Educ Behav 2014;46:412-7.

13. Park E. Overestimation and underestimation: adolescents' weight perception in comparison to BMI-based weight status and how it varies across socio-demographic factors. J Sch Health 2011;81:57-64.

14. Lee J, Sa J, Chaput JP, et al. Racial/ethnic differences in body weight perception among U.S. college students. J Am Coll Health 2018;66:42937.

15. Gross SM, Gary TL, Browne DC, et al. Gender differences in body image and health perceptions among graduating seniors from a historically black college. J Natl Med Assoc 2005;97:1608-19.

16. Chithambo TP, Huey SJ. Black/white differences in perceived weight and attractiveness among overweight women. J Obes 2013;2013:320326 
17. American College Health Association (ACHA). Generalizability, reliability, and validity analysis [Internet]. Silver Spring, MD: ACHA [cited 2016 Aug 1]. Available from: https://www.acha.org/NCHA/ NCHA/About/Generalizability_Reliability__and_Validity_Analysis_ NCHA_I.aspx.

18. Parcel TL, Menaghan EG. Measuring behavioral problems in a large cross sectional survey: reliability and validity for children of the NLS youth. Columbus, OH: Department of Sociology, The Ohio State University; 1988.

19. Schuna JM Jr, Johnson WD, Tudor-Locke C. Adult self-reported and objectively monitored physical activity and sedentary behavior: NHANES 2005-2006. Int J Behav Nutr Phys Act 2013;10:126.

20. Flegal KM, Carroll MD, Kit BK, et al. Prevalence of obesity and trends in the distribution of body mass index among US adults, 1999-2010. JAMA 2012;307:491-7.

21. Singh K, Mehta K, Shaikh NM, et al. Trabeculectomy with intraoperative mitomycin $\mathrm{C}$ versus 5 -fluorouracil. Prospective randomized clinical trial. Ophthalmology 2000;107:2305-9.

22. Riddle DL, Singh JA, Harmsen WS, et al. Clinically important body weight gain following total hip arthroplasty: a cohort study with 5-year follow-up. Osteoarthritis Cartilage 2013;21:35-43.

23. U.S. Department of Health and Human Services. Appendix 1. Translating scientific evidence about total amount and intensity of physical activity into guidelines [Internet]. Washington, DC: U.S. Department of Health and Human Services; [cited 2016 Aug 1]. Available from: https://health. gov/paguidelines/guidelines/appendix1.aspx.

24. U.S. Department of Health and Human Services. 2015 Poverty guidelines [Internet]. Washington, DC: U.S. Department of Health and Human Services; 2015 [cited 2016 Dec 15]. Available from: https://aspe.hhs. gov/2015-poverty-guidelines.

25. Janssen I, Carson V, Lee IM, et al. Years of life gained due to leisure-time physical activity in the U.S. Am J Prev Med 2013;44:23-9.

26. Bennett GG, Wolin KY. Satisfied or unaware? Racial differences in perceived weight status. Int J Behav Nutr Phys Act 2006;3:40.

27. Racette SB, Deusinger SS, Strube MJ, et al. Changes in weight and health behaviors from freshman through senior year of college. J Nutr Educ Behav 2008;40:39-42.

28. American College Health Association (ACHA). American College Health Association-National College Health Assessment II: reference group executive summary, Spring 2016 [Internet]. Hanover, MD: ACHA; 2016 [cited 2017 Mar 1]. Available from: https://www.acha.org/ NCHA/ACHA-NCHA_Data/Publications_and_Reports/NCHA/Data/ Reports_ACHA-NCHAIIc.aspx.

29. Tsai SA, Lv N, Xiao L, et al. Gender differences in weight-related attitudes and behaviors among overweight and obese adults in the United States. Am J Mens Health 2016;10:389-98.
30. Duncan DT, Wolin KY, Scharoun-Lee M, et al. Does perception equal reality? Weight misperception in relation to weight-related attitudes and behaviors among overweight and obese US adults. Int J Behav Nutr Phys Act 2011;8:20.

31. Christensen VT. Gendered perceptions of own and partner weight-level. Health (London) 2012;16:382-99.

32. Abbott BD, Barber BL. Embodied image: gender differences in functional and aesthetic body image among Australian adolescents. Body Image 2010;7:22-31.

33. Buote VM, Wilson AE, Strahan EJ, et al. Setting the bar: divergent sociocultural norms for women's and men's ideal appearance in real-world contexts. Body Image 2011;8:322-34.

34. Langellier BA, Glik D, Ortega AN, et al. Trends in racial/ethnic disparities in overweight self-perception among US adults, 1988-1994 and 1999-2008. Public Health Nutr 2015;18:2115-25.

35. Wharton CM, Adams T, Hampl JS. Weight loss practices and body weight perceptions among US college students. J Am Coll Health 2008;56:579-84.

36. Dorsey RR, Eberhardt MS, Ogden CL. Racial/ethnic differences in weight perception. Obesity (Silver Spring) 2009;17:790-5.

37. Oldham M, Robinson E. Visual weight status misperceptions of men: why overweight can look like a healthy weight. J Health Psychol 2016;21:1768-77.

38. Corral I, Landrine H, Hao Y, et al. Residential segregation, health behavior and overweight/obesity among a national sample of African American adults. J Health Psychol 2012;17:371-8.

39. Lim S, Harris TG. Neighborhood contributions to racial and ethnic disparities in obesity among New York city adults. Am J Public Health 2015;105:159-65.

40. Robinson E, Kirkham TC. Is he a healthy weight? Exposure to obesity changes perception of the weight status of others. Int J Obes (Lond) 2014;38:663-7.

41. Zajacova A, Burgard SA. Body weight and health from early to mid-adulthood: a longitudinal analysis. J Health Soc Behav 2010;51:92107.

42. Nelson MC, Larson NI, Barr-Anderson D, et al. Disparities in dietary intake, meal patterning, and home food environments among young adult nonstudents and 2- and 4-year college students. Am J Public Health 2009;99:1216-9.

43. Economos CD, Hildebrandt ML, Hyatt RR. College freshman stress and weight change: differences by gender. Am J Health Behav 2008; 32:16-25.

44. Sa J, Heimdal J, Sbrocco T, et al. Overweight and physical inactivity among African American students at a historically black university. J Natl Med Assoc 2016;108:77-85. 